\title{
ARQUEOLOGÍA ESPAÑOLA PARA UN NUEVO RÉGIMEN: Martínez Santa-Olalla y El nORTE de Marruecos*
}

\author{
Enrique Gozalbes Cravioto \\ Universidad de Castilla-La Mancha
}

Recibido: $14 / 07 / 2014$

Aceptado: $13 / 02 / 2015$

Revisado: 05/12/2014

Publicado: 30/05/2015

Resumen

El objetivo de la presente contribución es el de profundizar en la temática más general de la relación entre arqueología y africanismo en los inicios del régimen franquista, así como sobre todo documentar la protagonista actividad al respecto del jefe centralizado de la arqueología española, Julio Martínez Santa-Olalla. Estas actividades han sido analizadas en otras ocasiones en relación sobre todo al Sahara o a Guinea, sin embargo no se había constatado que un interés inusitado inicial se había centrado en el Norte de Marruecos, donde entre 1939 y 1941 el Comisario General de Excavaciones había realizado nada menos que cuatro viajes. Fue la oposición a sus actividades, sobre todo de Pelayo Quintero que estaba al frente de la arqueología en el Protectorado español, la que influyó en el desvío de su interés hacia otros lugares de África.

\section{Palabras Clave}

Historiografía de la arqueología; Tánger; Museo Arqueológico de Tetuán; Prehistoria de Marruecos; Franquismo.
ABSTRACT

The aim of the present contribution is to penetrate into the most general matter of the relation between archaeology and Africanism into the beginnings of the pro-Franco regime, as well as especially focus the study in the activity conducted by the chief of the Spanish archaeology, Julio Martínez Santa-Olalla. These activities have been analyzed in other occasions in relation especially to the Sahara or to Guinea, nevertheless there had not been stated that an unusual initial interest had centred on the North of Morocco, where between 1939 and 1941 the Commissioner General of Excavations had realized nothing less than four trips. It was the opposition to his activities, especially of Pelayo Quintero who was at the head of the archaeology in the Spanish Protectorate, which influenced the detour of his interest towards other places of Africa.

\section{KEYWORDS}

Historiography of Archaeology; Tangier; Tetuán's Archaeological Museum; Prehistory of Morocco; Franco's regime.

\footnotetext{
* Este artículo se enmarca dentro del proyectos de investigación: "Una arqueología sin fronteras. Los contactos internacionales de la Arqueología española en el siglo XX”(HAR-2012-34033).
}

enrique.gozalbes@uclm.es 


\section{ARqueOlogía EN UN EXTERIOR CERCANO}

La arqueología española en el exterior tiene su representación más directa y más cercana en la península Noroeste de Marruecos. Ello es así porque en buena parte dicha investigación histórica del patrimonio también ha sido en determinados momentos una arqueología del "interior". En primer lugar por la existencia de la Ciudad Autónoma de Ceuta, que une su carácter español con su ubicación en este territorio costero norteafricano. En segundo lugar porque la evolución histórica de la zona geográfica en cuestión, especialmente con la etapa representada por el Protectorado (1912-1956) supuso la creación española de una administración moderna, naturalmente con el establecimiento en esos momentos del servicio de arqueología, a partir de una primera legislación de tutela del patrimonio (1913), la creación de la Junta Superior de Monumentos Históricos de Marruecos (1919) y la primera inauguración del Museo Arqueológico de Tetuán (inicialmente en 1926, a la que siguieron otras recreaciones en 1931 y en 1940).

Este servicio de arqueología vivió situaciones bastante diferentes a partir de las personas que sucesivamente estuvieron a su frente: el aficionado explorador César L. Montalbán Mazas, desde 1921 hasta 1936 primero como "Asesor Técnico" y después (desde 1926) como Jefe de Excavaciones y Director del Museo Arqueológico de Tetuán, el anticuario Pelayo Quintero Atauri desde finales de 1939 hasta su fallecimiento en octubre de 1936, y finalmente el universitario Miguel Tarradell Mateu, que sucedió en sus cargos de inspector de Excavaciones y Director del Museo Arqueológico de Tetuán desde el año 1948 hasta la recuperación de la independencia por parte de Marruecos en el año 1956. Los momentos estelares de la arqueología, los de la dirección de M. Tarradell, se produjeron en los años cincuenta, con la celebración en Tetuán del Primer Congreso Arqueológico del "Marruecos español”, así como a partir de los contactos internacionales establecidos por dicho arqueólogo con los investigadores franceses del Magreb.

Hasta hace muy pocos años, la memoria de la arqueología española en Marruecos en la época del Protectorado estaba prácticamente perdida, muy especialmente en lo que se refería a las etapas anteriores a los estudios más modernos y con mayor documentación como eran los de M. Tarradell. No obstante, desde hace algunos años planteamos la necesidad de esa recuperación de la memoria, desde la amplia perspectiva de la moderna historiografía de la arqueología, a partir del análisis de la visión de la antigüedad en época franquista (Gozalbes, 2003). Muestras de este recrecido interés no faltan, entre ellas la celebración al respecto de coloquios diversos (Beltrán y Habibi, eds., 2008; Bernal, Raissouni y otros, eds., 2008), trabajos y publicaciones comolos especialmente centrados en algunos de los arqueólogos señalados anteriormente (Gozalbes, 2008; Parodi y Gozalbes, 2011, Gozalbes y Parodi, 2011, entre otros muchos), visiones realizadas sobre etapas más o menos amplias (Gozalbes, Parodi y Verdugo, 2013), o incluso monografías sobre la evolución de las aportaciones españolas a la arqueología del Norte de Marruecos (Gozalbes, 2012; 2012b). Así pues, después de todos estos trabajos, sin duda, componentes importantes de esa memoria histórica son ya suficientemente conocidos.

No volveremos ahora acerca de muchos de estos temas por encontrarse ya expuestos y desarrollados en los trabajos antes mencionados. Por el contrario intentaremos trazar algunas líneas sobre otros aspectos que continúan siendo muy poco conocidos y que afectan en este caso a los años inmediatamente posteriores a la Guerra Civil, unos momentos en los que ciertamente la conexión exterior estaba frenada para los arqueólogos, entre otras cosas, por el desarrollo de la Segunda Guerra Mundial (Gozalbes, 2014). Como es bien conocido, el periodo posterior a la Segunda Guerra Mundial fue el momento áureo de la arqueología en el continente africano (Robertshaw, 1990), y ello fue así precisamente por el interés de las potencias coloniales en utilizar la misma como propaganda; en la misma, la visión de África desde los orígenes humanos servía de elemento para el imaginario colonialista, en la exploración de los enigmas del continente "misterioso".

Precisamente el franquismo constituyó un ejemplo particularmente singular de lo que afirmamos. El régimen tenía en Marruecos su lugar "fundacional" en la medida en la que eran los militares africanistas los que encabezaron la sublevación. La colaboración marroquí, del Jalifa del Protectorado y de su gobierno, así como de los "voluntarios" marroquíes en el ejército, aumentó las simpatías mutuas. La política de la "hermandad hispano-marroquí", con el renacimiento cultural "hispano-árabe", condujo desde el punto de vista teórico a formular un renacimiento común de la cultura en España y Marruecos. La base de esa política, con su integrante cultural, se encuentra precisamente formulada 
en el plano teórico en la obra de un personaje, Tomás García Figueras, a partir de ahora T. G. F., que desde 1938 ocupó en el Protectorado una posición político-administrativa determinante.

Su obra titulada Marruecos, que se publicó el mismo año del final de la guerra, establecía la necesidad de desarrollo de los estudios, cuidando la "sociología musulmana marroquí, y mimando a éstos. Los nombramientos al frente de la arqueología del jubilado gaditano Pelayo Quintero, por otra parte viejo conocido suyo, y más tarde de Miguel Tarradell, por influencia en este caso de M. Almagro Basch, se debieron precisamente a su todopoderoso mandato en la administración del Protectorado. Esa política de hermandad cultural incluyó en un primer tiempo, el uso de rótulos, títulos e incluso hasta textos en árabe en las publicaciones de cultura y de arqueología que comenzaron a imprimirse en el Protectorado. Dicha voluntariosa actuación, emprendida en 1939, desapareció en 1942, puesto que en esa época ya la política de las reivindicaciones de España apuntaba más directamente a la evolución a una situación de construcción de un imperio a costa de las posesiones francesas, por tanto a un planteamiento más puramente colonialista.

\section{Martínez Santa-Olalla y el africanismo}

Desde el año 1938 J. Martínez Santa-Olalla mostraba sus aspiraciones y hasta planificaba la organización de un centralizado instituto arqueológico imperial, que tomaría directamente el modelo del alemán representado por el Instituto Arqueológico del Reich (Gracia, 2008). De hecho, en la primera planificación de zonas arqueológicas en España la arqueología del Protectorado marroquí quedó determinada como centralizada en el futuro desde Sevilla (Díaz-Andreu, 2002). Para Julio Martínez SantaOlalla (a partir de ahora J.M.S-O.) la arqueología de las plazas de soberanía (Ceuta y Melilla), Protectorado de Marruecos y colonias (se supone que Ifni, Tarfaya, Sahara Español, y Guinea Ecuatorial) tenía un interés excepcional: prueba de ello serían sus viajes y expediciones en los años subsiguientes, que le llevarían a Ifni en una ocasión, al Sahara al menos en dos, y por supuesto a Guinea Ecuatorial una vez. Esta actividad en el exterior aparece como un fenómeno absolutamente excepcional.

Sin embargo, cuando se creó la Comisaría General de Excavaciones Arqueológicas, África no estaba presente, y ni siquiera se encontraba recogido el ámbito del Protectorado español en el Norte de Marruecos, excluido de la red de las comisarías territoriales (Díaz-Andreu y Ramírez Sánchez, 2001). Ello sería así porque, pese a todo, legalmente el Protectorado se encontraba aparte de la administración gubernamental española, en la medida en la que allí existía una doble administración, la jalifiana que tenía algunas competencias, y la "protectora" que de hecho era autónoma de la española de forma que tenía su propia normativa. Sin embargo, para J. M. S-O. el protectorado marroquí, así como en su conjunto todo el continente africano, era una zona no ya importante sino básica desde el punto de vista científico y también de control del poder en la arqueología.

En efecto, África constituía para J. M. S-O. un elemento ideológico de primer orden, así como un fundamento esencial para el establecimiento del nuevo marco teórico que pretendía establecer en la arqueología prehistórica española. El nuevo orden que los todavía jóvenes investigadores simpatizantes del nuevo régimen querían establecer, que además servía para barrer a los viejos maestros como Bosch Gimpera, Gómez Moreno y hasta Obermaier y Taracena (en la pretensión de J.M.S-O.) que podían significar un "tapón” para los jóvenes. También significaba borrar esos componentes "africanistas" que se habían considerado existentes en el origen de las culturas primitivas españolas. Por el contrario, en África era donde de una forma más evidente que en Europa se mostraban las bases históricas más tradicionales del imperio español; a juicio de J.M.SO. que lo expresaría en diversas ocasiones, África era un continente siempre atrasado y primitivo, pasivo en la historia, incapaz de generar novedades importantes sino de (mal) recibirlas y adoptarlas a su manera.

Por eso el Neolítico se convertía en su "paletnología" en el llamado "Neolítico hispano-mauritánico", y las primeras Edades del Metal en la cultura "ibero-sahariana", en los que el elemento hispano era en todo momento el activo y protagonista que "colonizaba" culturalmente áreas próximas. Así pues, Marruecos constituiría un punto fundamental de estudio, sobre todo para demostrar que la cultura allí existente derivaba de la hispana, poseyendo mayor atraso que ésta. La lectura de prácticamente todos los trabajos de J. M. S-O. sobre Marruecos conduce a la misma conclusión: la búsqueda de esos hispanos presentes en el más cercano territorio exterior. Con ello en esos años se apoyaba intensamente la política de las "reivindicaciones" de Es- 
paña que pretendía sustituir a la decadente Francia en el imperio colonial norteafricano, la zona característica del "espacio vital" hispánico.

En una de sus publicaciones posteriores afirmaría que había estado en Marruecos en varias ocasiones en los años 1939, 1940 y 1941. Después de ello desvió su atención a partir del año 1942, con toda probabilidad y seguridad porque de hecho le puso el freno a sus actividades Pelayo Quintero Atauri, que dirigía la arqueología del Protectorado español desde finales de 1939. Así desde el año 1941 lo vemos ya presente en Sidi Ifni, en una expedición, en 1943 en otra bastante importante en el Sahara Occidental, y finalmente en 1946 en Guinea Ecuatorial, junto a la segunda expedición en el Sahara. Desde los apoyos y las buenas recepciones de las primeras, de forma creciente se vería obstaculizado con algunas resistencias. Ya la de Guinea constituyó todo un fiasco, por cuanto las autoridades en buena parte boicotearon y ridiculizaron su actividad y la de sus colaboradores.

El proceso terminó precisamente con su marginación absoluta de las actividades africanistas, pese a ser la máxima autoridad arqueológica española, pura paradoja en una época de triunfo absolutista de las jerarquías, junto a ser el director del "Seminario de Historia Primitiva del Hombre" de la Universidad Central (actual Complutense). Lo que había comenzado en Marruecos, con el freno puesto por P. Quintero, se fue extendiendo más tarde en la medida en la que el Comisario General de Excavaciones caía en el desprestigio personal, que el círculo del Marqués de Lozoya (Director General de Bellas Artes) extendía por doquier. Es significativo en el terreno de las colaboraciones: en el Archivo Español de Arqueología, promovido desde la Dirección General, Pelayo Quintero colaborará continuadamente, mientras J. M. S-O no lo hizo.

En 1945 en una reunión típicamente colonial, la Première Conference des Africanistes de l'Ouest, organizada en Dakar por los franceses, J. M. S-O. fue uno de los tres vicepresidentes, y personas de su equipo monopolizaron la presencia española con aportaciones diversas (Mederos, 2003-2004: 35), en lo que constituyó la intervención internacional más importante de la arqueología española en la época. Esta proyección internacional quedó rápidamente cercenada. Si continuó con su propia integración en la dirección permanente de los Africanistas, y con el intento de constituir el Comité Español de Africanistas, sin embargo en enero de 1947 el recién creado
Instituto de Estudios Africanos lo marginó dando la representación a Luis Pericot en el Primer Congreso Panafricano de Prehistoria celebrado en Nairobi.

En un golpe todavía más bajo, al mes siguiente su programada participación en la II Conference des Africanistes de l'Ouest se vió cercenada al no recibir el visado gubernamental de salida para poder acudir a Bissau en la Guinea portuguesa, sin duda una grave afrenta que tan sólo un régimen dictatorial podía hacer nada menos que con el jefe de la arqueología española. El Conde de Castillo-Fiel $(1948,44)$ afirmaría en la reseña de la participación española en la revista del Instituto de Estudios Africanos, que la representación tenía que estar formada por él mismo, por Francisco Hernández Pacheco y por Martínez Santa Olalla: “el Dr. Martínez Santa Olalla, que había anunciado la presentación de numerosos trabajos en el Congreso, decidió no asistir al mismo ni presentar las comunicaciones prometidas. Por otra parte fue Hernández Pacheco quien fue elegido miembro del Comité Permanente en sustitución de Santa Olalla, que a partir de ese momento desaparecería de la nómina de colaboradores del Instituto de Estudios Africanos.

Por el contrario, su lugar sería en el mismo ocupado por Luis Pericot García, quien participaría en los Congresos Panafricanos de Prehistoria hasta el de Adis Abeba en 1971, y además logró la aspiración del otrora Comisario, el llevar en 1963 uno de estos eventos internacionales a las islas Canarias. Años atrás había además presidido el Congreso Internacional de Ciencias Prehistóricas y Protohistóricas celebrado en Madrid, ocupando con ello el protagonismo principal de la arqueología prehistórica española, en el evento internacional más importante. No cabe duda de que lo que se había iniciado en el Protectorado marroquí, la resistencia a su control y presencia, proseguido por su marginación en el Instituto de Estudios Africanos, se extendió hasta lo que significaría años más tarde su caída definitiva.

Martínez Santa Olalla en Marruecos: 1939

Como hemos señalado anteriormente, J.M.S-O. afirmaba que había estado en viajes arqueológicos en Marruecos, en los años 1939, 1940 y 1941. En realidad los mismos resultan difíciles de documentar, de tal forma que apenas hablan de ellos, no se aportan apenas datos, los que han tratado sobre las actividades africanistas del personaje. Pese a todo, es indudable que desarrolló esas actividades, en algunos de los casos acompañado (en 1939) por Carlos 
Alonso del Real, y en los posteriores de su fiel colaborador Bernardo Sáez Martín. Debe reconocerse su interés y su voluntad por la arqueología, más allá de la lucha de poder y protagonismo, pero es cierto que resulta difícil separar la palabrería y la presunción, pese a que en parte realizó publicaciones acerca de sus actividades.

Ahora bien, destaca el que en su curriculum vitae personal, conservado en el Museo de San Isidro en Madrid, en el que presumía de participar en numerosas excavaciones en el extranjero, en África incluye su supuesta participación en las de Tit Mellil, Volubilis y Achacar (Ortega y Quero, 2002, 202). Detrás de estos datos se encuentra simplemente una falsedad, propiamente son mentiras, como veremos a continuación pues las referencias concretas que realiza al respecto resultan de todo punto sorprendentes.

La participación en la excavación de Tit Mellil es simplemente imposible. Este yacimiento prehistórico fue excavado por M. Antoine entre los años 1926 y 1933, con publicación de los resultados en el año 1938, y es materialmente imposible que J. M. S-O. pudiera participar en esas excavaciones. Sin embargo, es muy probable que la referencia corresponda a una visita sin una mayor huella, acompañado del propio Antoine, realizada a finales del verano de 1939 a este yacimiento de Casablanca; debe tenerse en cuenta que Antoine no tenía cargo oficial, era un aficionado que realizaba las excavaciones bajo el amparo de la Société de Préhistoire du Maroc, que se vería halagado en atender en 1939 al jefe de la arqueología española. En un trabajo de 1941 J. M. S-O. confundirá nada menos que con el "Asturiense" los guijarros tallados en forma de pico del Paleolítico Inferior en una particularmente disparatada interpretación (Souville, 1973: 321) destinada sin duda a explicar, una vez más, la presencia de hispánicos en Marruecos.

Tan sorprendente todavía es la referencia a excavaciones en la ciudad romana de Volúbilis, con casi total seguridad se trató simplemente de una visita, probablemente tomando contacto en la misma con R. Thouvenot que era el director del Servicio de Antigüedades del Marruecos francés. No hay huellas de su paso, ni consta oferta alguna de colaboración posterior, pero debe tenerse en cuenta que la estrecha relación de R. Thouvenot con España, donde había empezado a ejercer, no debió ayudar al prestigio de quien en no pocas ocasiones la fama o precedía o perseguía.
El caso de Achacar en Tánger, sin embargo, puede ser más indicativo de una realidad, de un cierto nivel de participación en los trabajos. Creemos que muy posiblemente en este año 1939 J. M. S-O. visitó las exploraciones que en Mougharet el-Aliya, la "High Cave" como la llamaron, realizaban dos aficionados norteamericanos, el médico R. Nahon y el encargado oficial de negocios en Tánger, H. E. Doolitle. Estas actividades a pico y pala en realidad tenían mucho de simple expolio en una zona colonial de África.

De ahí vendría el sumo interés mostrado por J. M. S-O. en todo momento acerca de la gran cueva de Achacar. En efecto, en el año 1946 volvió al lugar, cuando ya actuaba en el mismo la Misión Antropológica Americana, en cuya publicación preliminar, su director H. Hencken (1948, 282) mostraba de una forma expresa su agradecimiento al profesor J. M. S-O. por la segunda visita realizada (luego hubo una anterior a ese momento) y por las informaciones y el asesoramiento ofrecido a los norteamericanos. Esta mención del contacto con su segunda visita indica que la primera con casi seguridad debió producirse en el verano del año 1939, marchado ya S. Coon de Tánger (quien participó y asesoró durante un par de semanas a los dos aficionados) pues en junio de 1940 ya se habían suspendido las excavaciones con la entrada de los españoles en la ciudad.

La cueva tangerina y algunos de sus materiales fascinaron a J. M. S-O. puesto que así lo reflejarían en la revista de su grupo de investigación, los Cuadernos de Historia Primitiva. Así Carlos Alonso del Real escribiría sobre "Fósiles humanos de Tánger”, reseñando la aparición de un fragmento óseo de un niño que los americanos clasificaban como Neanderthal. En el mismo año de 1946 el propio J. M. S-O. publicaba un interesante trabajo titulado "¿Solutrense en África? Los hallazgos paleolíticos de Tánger". Se trataba de una importante aproximación, una de las primeras que se realizaban en relación con los hallazgos por parte de los aficionados americanos de las puntas pedunculadas del Ateriense en Mougharet el-Aliya. Las mismas se asemejaban bastante a las del Solutrense de la cueva valenciana de Parpalló.

Si para los franceses resultaría simple convergencia y no relación entre el Ateriense y el Solutrense, sin embargo J. M. S-O. influirá en los norteamericanos para interpretar que los restos marroquíes mostraban el paso de los solutrenses hispanos al Norte 
de Marruecos. Pocos años más tarde, en 1949, J. M. S. O. volvía a tratar sobre la cueva y mostraba interés por sus materiales. En todo caso, L. Pericot realizaría una interpretación justamente contraria: las piezas de Tánger mostrarían una influencia del Ateriense norteafricano en el Solutrense hispano.

La expedición de 1939 fue sin duda fructífera como primer conocimiento del país: aparte del Marruecos francés, y de la visita al Tánger internacional, el personaje aprovechó para justificar un conjunto de investigaciones en ocasiones más imaginarias que reales. En su publicación de 1945 indicaba de pasada, sin mayores precisiones, un comentario al pie de una fotografía del monumento de Mezora: "se estudiaron exhaustivamente conjuntos como el famoso de Mezora, que se centra en torno al Uted" (Martínez Santa-Olalla, 1945, 24). Se trataba éste de un monumento megalítico que ya había atraído su atención en 1935, aunque en aquel caso a partir de la publicación de un prehistoriador francés: ahora tenía ocasión de conocer directamente el lugar. $\mathrm{Cu}-$ riosamente, en la ampliación de esta información en 1947 a J. M. S. O. le debió dar algo de vergüenza hablar de un "estudio exhaustivo" en lo que había sido indudablemente una simple visita y no alude a ello. Nunca publicó nada que indicara realmente un estudio detallado del conjunto arqueológico.

Sin embargo, caso distinto es el de la localización del yacimiento de superficie con silex en el Zoco del Tnin de Sidi Yamani. Aunque no existan precisiones acerca del momento, creemos que el descubrimiento se debió realizar en esta visita ya que este Souq o poblado con mercado semanal era entonces casi necesariamente, y hoy suele continuar siéndolo, el punto de partida para ir al pequeño poblado donde se halla el monumento megalítico. Este yacimiento de superficie del Tnin de Sidi Yamani era considerado muy rico en silex y lo clasificó en el Neolítico (Martínez Santa-Olalla, 1945, 22; 1947, 9).

El paso de J. M. S. O. por el Marruecos español ha dejado huella hasta ahora desconocida en la documentación. En efecto, en el mes de agosto había accedido el mencionado Tomás García Figueras a la Secretaría General de la Alta Comisaría. El contacto con el Comisario General de Excavaciones ilusionó a T. G. F. quien puso en marcha medidas para poder desplegar la arqueología en la política de la hermandad cultural hispano-marroquí. Decidió que lo atendiera C. L. Montalbán en el Museo de Tetuán, en cuyos Archivos se conserva la documentación (autorización de estudio de los archivos del Museo
Arqueológico de Tetuán de la Direction du Patrimoine Culturel du Maroc en abril de 2013).

En un documento de esta época, firmado por C. L. Montalbán y con el título de "Trabajos necesarios para la conservación del cromlech de Mzora", se planteó restaurar la valla de protección, que había sido asaltada en 1936, así como una limpieza del lugar y una pequeña obra de consolidación a partir de la evacuación de aguas. Con toda probabilidad este apunte se realizó a consecuencia de la estancia de J. M. S-O. y de su somero estudio en el monumento megalítico. Se indicaba la necesidad de restaurar la protección del monumento, desaparecida después de julio de 1936 cuando Montalbán fue detenido a punta de fusil por las tropas sublevadas, y que fue seguida más tarde por un saqueo por parte de los lugareños.

En esta estancia en Tetuán, J. M. S-O, transmitió a Montalbán un auténtico programa de acción que éste plasmó en documento que se conserva en el Archivo del Museo Arqueológico de Tetuán, titulado "Notas relativas al viaje del Sr. Santa-Olalla" fechado el 19/10/1939, lo cual indica que con total seguridad la estancia en Tetuán se produjo entre finales de septiembre y la primera quincena de octubre. Se trata de una simple cuartilla escrita a máquina, con casi total seguridad por parte de C. L. Montalbán, puesto que es la misma máquina y estilo del documento anterior. En este documento se recogen una serie de ideas o instrucciones dadas por el Comisario para su desarrollo en el futuro.

Un año más tarde Pelayo Quintero, nombrado a fines del año como Director del Museo Arqueológico de Tetuán, aludiría a la existencia de todo un programa diseñado por la "superioridad" de la Alta Comisaría. A nuestro juicio el tal "programa” no era otro que estas ideas transmitidas por J. M. S-O. en un momento en el que, favorecido por el vacío, quiso ejercer su autoridad en la arqueología del Protectorado. Entre las mismas encontramos explicitados los datos siguientes: una campaña de investigación en el monumento de Mezora, aprovechando las vacaciones de Semana Santa durante tres semanas, sendas conferencias que el Comisario debía pronunciar en Navidad en Tánger y en Tetuán, envío del restaurador del Museo Arqueológico de Tetuán, establecimiento de guardas en las ruinas del Protectorado, la publicación de un trabajo sobre arqueología (se supone del Norte de Marruecos) para final de año, preparación del catálogo moderno de las piezas que guardaba el Museo Arqueológico, así 
como establecer el listado y la publicación científica de las inscripciones del Museo Arqueológico.

El plan establecido por J. M. S-O. fue asumido como el de la "superioridad" y realmente era muy sensato. $\mathrm{Y}$ también de hecho en buena parte se cumplió. El estudio arqueológico, ahora sí, del monumento de Mezora durante tres semanas, aprovechando las vacaciones escolares de J. M. S. O., no se realizó pero sí como veremos se dieron las conferencias en las dos ciudades. La publicación del trabajo arqueológico tendrá el recorrido que podemos suponer por la documentación que luego utilizamos. La plaza de restaurador sería sustituida a corto plazo por la que se puso en ejecución poco tiempo más tarde, la de Conservador (ocupada por Cecilio Giménez Bernal). En años sucesivos se establecieron "guardas" por simple gratificación en Tamuda y en Lixus. Y P. Quintero encargaría al P. César Morán el estudio y publicación de las inscripciones latinas. El nuevo Director del Museo Arqueológico consideró que era preferible dejar para más adelante el catálogo del mismo, y lo sustituyó por el estudio de determinadas piezas que fue publicando, y después reunió en un libro.

\section{PROYECTOS, REALIDADES Y FANTASÍAS: 1940}

Indudablemente fue también entonces cuando T. G. F., desde la Secretaría General de la Alta Comisaría, aprovechó el prestigio y autoridad del personaje para encargar a J. M. S-O. la elaboración de unos cuestionarios. Los mismos constituirían una encuesta por las cabilas o aldeas del Protectorado para obtener información sobre vestigios arqueológicos y monumentales. Se trataba de un proyecto muy querido por el administrador colonial, que recordaba los realizados en época de Primo de Rivera (año 1928) y él mismo potenciaría alguno que otro bastantes años más tarde en relación con la Etnografía.

Sin duda, la satisfacción del Comisario General de Excavaciones debió ser muy evidente, en la medida en la que estaba consiguiendo tomar protagonismo e introducir la arqueología marroquí bajo su autoridad. En este sentido, incorporó al proyecto a sus colaboradores más cercanos. Así J. Pérez de Barradas, con quien todavía mantenía una estrecha relación que luego se cortaría, recibió el encargo de elaborar el cuestionario de Etnología, el más estrecho colaborador de J. M. S-O. en esos momentos como era C. Alonso del Real redactaría el de Linguïstica, y finalmente J. M. S-O. el cuestionario concreto de Arqueología. Los cuestionarios se publicarían el 1 de octubre de 1940, de forma expresa "fiesta del Caudillo", y su presentación sin nombre está elaborada por la "Secretaría General de la Alta Comisaría" (es decir, García Figueras) que realiza una loa al Jalifa y a la gestión de los Altos Comisarios Beigbeder y Asensio, con una labor caracterizada por "gran vitalidad".

Como curiosidad, esa presentación de los Cuestionarios indicaba que Pérez de Barradas era profesor de Antropología de la Universidad de Madrid y Director del Museo Etnológico Nacional, Alonso del Real era licenciado en Filología Clásica y Secretario de la Comisaría de Excavaciones y J. M. S-O. era profesor de Arqueología de la Universidad de Madrid y Comisario Nacional de Excavaciones. En la introducción del cuestionario de Arqueología, J. M. S-O. recogía afirmaciones que eran bien significativas; en primer lugar, señalaba que la disciplina de la arqueología se refería de una forma exclusiva al África pre-islámica, no queriendo saber nada del Islam cuyo estudio correspondía simplemente a la "Historia del Arte"; en segundo lugar que con el Norte de África incorporado a su título en realidad se refería a toda la zona hispana de África, "desde la línea costera del Oranesado hasta la línea del Senegal y la gran curva del Niger al sur de Tombuctú.... que con nuestras islas atlánticas y la Península forma en determinadas épocas prehistóricas unidad bien definida” (Martínez Santa-Olalla, 1940, 47).

Los planes diseñados en septiembre-octubre por parte de J. M. S-O. se cumplieron en buena parte. En la visita de 1940 sí se realizaron las conferencias en Tetuán y en Tánger, que además figuran en el curriculum personal conservado en el Museo de San Isidro. En concreto, la conferencia en Tetuán se pronunció en el Centro de Estudios Marroquíes el 29 de enero de 1940 y versó sobre "Orígenes de la Nacionalidad Hispánica” (Valderrama, 1956, 521). La conferencia en Tánger, por las mismas fechas, debió versar sobre idéntica temática pero no hemos encontrado documentación acerca de la misma. Ahora bien, desde el terreno práctico J. M. S-O. sin duda en este viaje pudo percatarse de que la arqueología en el Protectorado ya tenía a un entusiasmado Pelayo Quintero al frente. Ello significaba un claro límite a su actuación: Quintero tenía una fuerte personalidad y por su edad y trayectoria difícilmente se le podía puentear. El proyecto de los cuestionarios ya estaba en marcha y P. Quintero mostraría siempre hostilidad hacia los mismos. 
Es poco dudoso que el carácter de uno y de otro generó tensiones: J. M. S-O. era "áspero con los colegas”, irónico y desdeñoso (Caro Baroja, 1972, 364) y Pelayo Quintero poseía también un carácter bastante fuerte, al mismo tiempo bondadoso con los jóvenes pero desde la edad y la trayectoria poco amigo de aguantar intromisiones y menos lo que pudiera considerar impertinencias. Basta con leer los trabajos de esta época, del uno y del otro, para poder detectar que se ignoraron, silenciaron de una forma absoluta sus actuaciones y sus estudios. Para el falangista Quintero podía representar precisamente esa España "caduca" del pasado, mientras éste difícilmente podía entenderse con quien insultaba no ya a la democracia sino al liberalismo decimonónico que él profesaba.

Fue entonces cuando J. M. S-O. consiguió de T. G. F. el apoyo inicial a un proyecto importante y hasta ahora absolutamente desconocido, en la línea con las investigaciones y publicaciones sobre Marruecos. En la correspondencia posterior entre los dos personajes que se conserva en el Museo de Tetuán podemos observar la realidad de ese interesante proyecto de elaboración de unas Fontes Mauritania Antiquae. El proyecto de J. M. S-O. tiene sus evidentes paralelismos con las Fontes Hispaniae Antiquae de A. Schulten y P. Bosch Gimpera, que incluso habían continuado publicándose en Barcelona durante la Guerra Civil.

En la documentación del Archivo del Museo aparece referencia a que había que recoger toda una serie de textos clásicos, griegos y latinos, bajo la dirección de J. M. S-O. y que serían publicados por el recién creado "Instituto General Franco" para la investigación hispano-marroquí, órgano para canalizar las investigaciones españolas sobre el Protectorado. De la recopilación y traducción de los textos griegos se encargaría Carlos Alonso del Real, segundo de J. M. S-O. en la Comisaría y después catedrático de la Universidad de Santiago de Compostela y finalmente de Prehistoria en la Complutense, mientras que de los textos latinos se ocuparía Ramón Fernández Pousa, ideológicamente también muy adicto al régimen franquista, que ese mismo año presentó su tesis doctoral, y desde 1949 fue catedrático de Filología Latina en la Universidad de Murcia.

El trabajo era ciertamente ambicioso. Se trataba de desarrollar una recopilación plural de fuentes para el estudio del Marruecos prehistórico y antiguo, con lo que se llenaba un vacío muy evidente de la historiografía española. En este sentido, en carta fechada en el 25/01/1940 ya J. M. S-O. le indicaba a T. F. G. que el proyecto de la Fontes Mauritania Antiquae estaba en muy directa relación con otra publicación necesaria y relacionada titulada "Estampas arqueológicas del Magreb". Sin duda, aquí tenemos el proyecto expresado en la visita del verano anterior, que había quedado paralizado, el de realizar una publicación arqueológica, destinada sin duda a que J. M. S. O. recogiera sus estudios y visitas arqueológicas en Marruecos.

A partir de ese momento, la documentación del Museo Arqueológico de Tetuán muestra que la concreción del proyecto quedó en manos de Carlos Alonso del Real. Éste en carta a T. G. F. el 15/02/1940 expresaba su profunda satisfacción por el apoyo mostrado a J. M. S-O. en relación con el proyecto, y mencionaba algunos datos y problemáticas en relación a la edición de los textos griegos, latinos e incluso hebreos, señalando la necesidad de disponer de una imprenta muy profesional y especializada, de la que por otra parte se carecía en Tetuán en esos momentos, así como de la conveniencia de incluir bibliografía en la publicación. El 19/02/1940 le contestó T. G. F. observando la existencia de un exceso de generalidades en los datos que aportaba Alonso del real, y pidiendo una mayor concreción en relación con el desarrollo que debía tener el trabajo. En carta del 13/03/1940 el propio T. G. F. contestaba a los planteamientos de Alonso del Real concretando los problemas de una edición crítica del famoso Periplo de Hannon, al indicar que el mismo debía ir acompañado de unos croquis y de algunas notas explicativas.

Esta carta del mes de marzo de 1940 es la última en la que hemos encontrado referencias al ambicioso proyecto de la elaboración de las Fontes Mauritania Antiquae. Sin demasiado aventurarnos creemos que Pelayo Quintero logró frenar el proyecto que se introducía en su ámbito, y desde luego los interlocutores no mantuvieron un continuado interés acerca del mismo. Bastante tuvo sin duda T. G. F. manteniendo el reto que supuso la publicación de los "Cuestionarios" como así se hizo algunos meses más tarde. Porque de forma poco operativa y comprensible las respuestas no se hacían, al menos en la parte de Arqueología, al Museo Arqueológico, sino como expresamente se indica en los mismos a la "Junta Central de Monumentos" afecta a la Secretaría General de la Alta Comisaría.

Los cuestionarios dieron algunos resultados, pero de una forma dispersa. J. M. S-O. hubiera que- 
rido controlar los mismos desde la Secretaría General del Protectorado, y ese era sin duda el fundamento de que a éste fuera a quien se dirigieran en su casos las contestaciones. Pero T. G. F., si en buena parte controlaba la información y guardó temporalmente el equilibrio con P. Quintero, con fecha 1 de enero de 1942 pasó a ejercer de Delegado de Educación y Cultura. A partir de ese momento las respuestas a los cuestionarios de arqueología realizadas por los interventores territoriales se hicieron al Museo Arqueológico y, en efecto, en los cajones de los mismos se encuentran cartas de los años 1942 a 1946 con materiales remitidos por estos agentes. Con ello J. M. S-O. terminó ya absolutamente de tener presencia en la arqueología del Protectorado, razón por la que dirigiría su atención desde Ifni a finales de 1941, el Sahara Español sobre todo (ya en 1943) y finalmente Guinea Ecuatorial (1946). Pero entre una situación y la otra quedan dos visitas en 1940 y 1941.

El Canto del cisne en Marruecos: finales de 1940 y 1941

En realidad fue en el otoño del año 1940 y en el de 1941 cuando J. M. S-O. realizó las expediciones más importantes a Marruecos. En una publicación donde aclara algo más la cronología de sus actividades, y señala la realidad de la existencia de una tercera expedición en otoño de 1940, parece aclararse que la misma se centró en un viaje de estudios realizado con alumnos de la Universidad (que se lo pagaron ellos mismos) y con sus colaboradores a la ciudad de Tánger. Debe tenerse en cuenta que en ese verano la ciudad internacional había sido ocupada por las tropas de Franco, por acuerdo ante el desarrollo de la Guerra Mundial. Allí sin duda el Comisario de Excavaciones encontró la posibilidad de investigar y de actuar mucho más a sus anchas, sin entrar en contradicción con Pelayo Quintero quien nunca mostró mayor interés por la ciudad tangerina. Fiel a su peculiar estilo, en la publicación J. M. S-O. se quejaba con amargura de no haber recibido apoyo ni subvención alguna, más allá de las facilidades para la locomoción dadas por la Alta Comisaría, indudablemente T. G. F. a quien de una forma significativa ya ni siquiera cita por su nombre.

Según afirmaba J. M. S-O., "nos propusimos como objetivo una exploración del país o, por mejor decir, una prospección, que nos condujo a descubrir una serie de yacimientos....”. E indicaba la diversidad de los mismos en Tánger: unos esta- ban al aire libre, otros se hallaban en cuevas como la de Mougharet el-Aliya "que por aquel entonces excavaban los norteamericanos" (se refiere indudablemente a la visita previa de 1939), sepulcros megalíticos tangerinos que se destrozaron con posterioridad, ruinas de la Tánger de época púnicomauritana "perfectamente localizada por nosotros" y en la que trabajos de urbanización posteriores habrían ocasionado graves destrozos; afirmaba que las cuevas de Achacar fueron visitadas en el curso de este viaje de estudios y que corrían severo peligro de destrucción, como así era pues los españoles habían situado una batería antiaérea en el lugar (que no se atreve a mencionar).

Aparentemente por las presunciones, las actividades de J. M. S-O. condujeron al conocimiento de algunas tumbas del horizonte de la Edad del Bronce, formadas por lajas de piedra, que serían destruidas en obras posteriores, pero no identifica el lugar de las mismas; de igual forma, las obras urbanas probablemente acometidas por los españoles en el casco urbano de Tánger dieron como resultado restos de la ciudad prerromana que el Comisario de Excavaciones pudo observar pero por desgracia nuevamente no explicita lo más mínimo al respecto. Pero los restos más evidentes, puesto que fueron los únicos mencionados expresamente, fueron los de "yacimientos al aire libre" entre los que sin duda destacaron dos, con silex prehistóricos.

- El primero de ellos fue el del cementerio musulmán de Sidi Amar, "descubierto por el Seminario de Historia Primitiva del Hombre en un viaje de estudios a Marruecos" (Martínez Santa Olalla, 1945, 22; 1947, 9). Las piezas recogidas en el mismo le permitían incluirlo en el Neolítico. Por su parte C. Posac, que revisaría las piezas algunos años má tarde, consideraba que las mismas correspondían a hojillas de doroso rebajado de pequeñas dimensiones, con presencia de buriles, y afirmaba que se asemejaban mucho a las descubiertas por él en algún yacimiento de la zona de Melilla (Posac, 1949, 123).

- El segundo de los yacimientos fue el único publicado de una forma monográfica, en la zona oriental del jebel dar Shriro, en el lugar de Aïn Dalia Seguir. Allí señalaba haber recogido una treintena de piezas sobre las que afirmaba en nota: "estos hallazgos tangerinos de que hoy nos ocupamos, salvo el pico, fueron depositados como los de otras localidades en el Museo Arqueológico de Tetuán, sin haber podido lograr su entrega posteriormente (?). Algunos de nuestros hallazgos figuran expuestos en 
dicho Museo o hay referencias impresas sin citar su origen". La descripción de las piezas permite detectar la existencia de denticulados, elementos de hoz, que indicaba un yacimiento de la cultura de hojas (Iberomauritano) muy avanzada, ya en el Neolítico. Pero fiel a su constante interés, J. M. S. O. identificaba nada menos que como "campiñense" un "pico" cuyo dibujo publica. Esta cultura "campiñoide" del Neolítico avanzado vendría del África Occidental, a su juicio no significaría un origen hispano "de nuestro neolítico campiñoide tangerino" (Martínez Santa Olalla, 1947b, 51).

La última expedición de J. M. S-O. a Marruecos se produciría pocos meses más tarde. Con toda probabilidad el resultado más importante de los mencionados Cuestionarios, muy mal vistos por P. Quintero, fue el del descubrimiento de las pinturas rupestres de Magara Sanar en el yebel Kasba, en la zona interior montañosa de Jbala. El interventor territorial informó de la existencia de las mismas: en su publicación J. M. S. O. blasonaría de que el hecho se debía a sus magníficos Cuestionarios. Al tener noticia del hallazgo, organizó una nueva visita a Marruecos, que aclara realizada en el mes de noviembre de 1941, y que en el viaje hasta el lugar participaron sus colaboradores Simeón Giménez Reyna, Jorge Rein Segura y Bernardo Sáez Martín. La misión de J. M. S-O. copió en acuarela las pinturas, pero sobre todo realizó un magnífico reportaje fotográfico, algunas de cuyas producciones se pueden ver en las dos publicaciones que $\mathrm{J}$. M. S-O. dedicó a la publicación de las pinturas en 1941 y 1943.

El estudio descriptivo de J. M. S. O. sobre las pinturas es bastante válido desde el punto de vista técnico, con la expresión del uso del color rojo formado con óxido de hierro e indicios de cobre, el estilo de líneas de puntos y figuras esquemáticas (entre ellas sobre todo un hombre montado a caballo). Naturalmente no podía menos que incluir la interpretación dentro de sus cauces: "indudablemente son la obra de neolíticos andaluces, cuyos orígenes artísticos se hallan en las pinturas impresionistas del neolítico del Levante español” (Martínez Santa Olalla, 1941, 442).

En todo caso, resulta curioso el que Pelayo Quintero asumiera el descubrimiento de las pinturas, a las que dedicó una breve noticia en la revista Archivo Español de Arqueología, así como en su obra de 1941. Realiza una breve descripción de las características de las mismas, destaca la figura del hombre montado a caballo, así como las otras figuras pintadas que aparecían. Pero pese a todo, Quintero silencia el hecho del estudio que realizaba en esos momentos J. M. S-O., quien a su vez silenció en sus publicaciones en todo momento al inspector de excavaciones y director del Museo. No cabe duda alguna de que cada uno hacía todo lo posible por ignorar al otro.

Otros datos, aparte de la exploración de las pinturas, conocemos acerca de la expedición de noviembre de 1941. En su agradecimiento en nota a pie de página a Giménez Reyna, Rein Segura y Sáez Martín, se incluye el agradecimiento a T. G. F. por las "atenciones de que fuimos objeto y a las facilidades dadas para nuestros estudios, tanto oficial como particularmente”. Y además señalaba que la expedición había dado por resultado el "descubrimiento más tarde de toda una serie de localidades prehistóricas que enriquecen el mapa arqueológico de Marruecos” (Martínez Santa Olalla, 1941, 438). Nos hallamos ante una presunción sin posible constatación, pues en sus publicaciones africanistas de 1945 y 1947 no dice nada al respecto, salvo que se encierre en la referencia imprecisa a "culturas arqueolíticas de talla bifacial de lascas y hojas procedentes de los márgenes del Lucus, del Martín, del Lau, del Muluya...." (Martínez Santa Olalla, 1945, 22; 1947, 9).

\section{CONCLUSIONES}

El estudio que hemos realizado confirma el sumo interés que después de la Guerra Civil tuvo por el continente africano el nuevo Comisario General de Excavaciones. Este hecho ha sido bien destacado por algunos estudios en los últimos años, y hemos podido comprobar como al respecto se planteó una lucha por la presencia en la arqueología en el exterior. Es bien sabido que en la pugna, J. M. S-O. terminaría siendo duramente derrotado por sus rivales. Pero siempre se ha mencionado el Sahara, subsidiariamente Guinea, como los elementos de esa lucha, mientras a Marruecos se le concedía un papel secundario. Sin embargo, como hemos creído demostrar en el presente trabajo, la atención del Comisario General se dirigió prioritariamente hacia Marruecos, y sólo fue después de ver frenada su intervención allí cuando dirigió la atención a los otros objetivos.

Entre el verano de 1939 y el otoño de 1941 J. M. S-O. realizó nada menos que cuatro viajes al Norte de Marruecos, que hemos documentado en sus 
actuaciones a partir de la documentación inédita (archivo del Museo Arqueológico de Tetuán) y de las generalidades y presunciones recogidas en sus propias publicaciones. Proyectos de presencia e influencia en la arqueología marroquí que evidencian no sólo el interés científico por África, sino también una voluntad de poder y de control en la arqueología del Protectorado, fomentando también la participación de sus colaboradores. El hecho de que en este interés terminara fracasando, lo que motivó la búsqueda de otros objetivos, no significa que fueran irrelevantes sus intentos. Será después cuando en sus publicaciones aparecerán formulados los reproches acerca del vacío creciente: no contó con ninguna ayuda económica ni con un fomento especial de la investigación, aunque en el personaje de T. G. F. siempre buscara, y de hecho encontrará, un apoyo logístico y de transportes. Lo cierto es que en la pugna de competencias, Pelayo Quintero logró mantener la arqueología del Protectorado fuera del control del ambicioso falangista, y los modestos presupuestos para arqueología fueron controlados por él.

Desde el punto de vista de la aportación estrictamente arqueológica, más allá de las exageraciones y de las propagandas que hemos desvelado con claridad, como en el caso del monumento megalítico de Mezora, es cierto que J. M. S. O. intentó trazar unas relaciones internacionales, con los norteamericanos en Tánger, con los franceses en el Marruecos francés. Pero muy probablemente, sobre todo con los segundos, que eran más conocedores de la arqueología en el territorio, sus limitaciones personales quedaron bien en evidencia. Pese a todo, debe reconocerse que J. M. S-O. tenía personalidad, realizó sus propias interpretaciones, de unos alcances muy diferentes y a veces hasta pintorescas, buscando en todo momento justificar la colonización de Marruecos por primitivos españoles. Menciona alguna bibliografía, y el mediocre método arqueológico ciertamente era el mejor posible en la España de su época. Pero el estudio sobre las pinturas rupestres del Magara Sanar, de carácter esquemático y analizadas con soltura, su aportación sobre el Neolítico de al menos tres yacimientos nombrados y descubiertos en sus viajes, resultan algo relevantes. Su mención sobre las tumbas tangerinas, o sobre los vestigios urbanos prerromanos, señalan la constatación de lo que intuimos: la profunda alteración y destrucción de materiales arqueológicos provocada en Tánger por las obras urbanas.
Publicaciones de Martínez Santa-Olalla sobre el Norte de Marruecos

(1935) "Monumentos megalíticos de Marruecos", Actas y Memorias de la Sociedad Española de Antropología, Etnografía y Prehistoria, 14 (2-3), 262-263.

(1940) "Cuestionario de Arqueología norteafricana", Investigación científica de Marruecos. Cuestionarios de Etnología, Lingüistica $y$ Arqueología, Larache, 47-61.

(1941) "Las primeras pinturas rupestres del Marruecos Español", Actas y Memorias de la Sociedad Española de Antropología, Etnografía y Prehistoria, 16 (3-4), 438-442.

(1942) "Die höhle Yebel Kasba in Neues über prähistorische Felsmalereien in Frankreinch, Spanien und Marokko”, Jahrbuch Prähistorische und Etnographische Kunst, 15-16, 22-24.

(1943) "Los andaluces en Marruecos durante el Neolítico. Las primeras pinturas rupestres del Marruecos español”, África, 18, 9-11.

(1945) "El africanismo en la Universidad y el Seminario de Historia Primitiva del Hombre", África, 46-47, 20-26.

(1946) “¿Solutrense en África? Los hallazgos paleolíticos de Tánger”, Cuadernos de Historia Primitiva del Hombre, 2, 97-101.

(1947) África en las actividades del Seminario de Historia Primitiva del Hombre, Madrid.

(1947b) "Campiñense en Marruecos: el pico de El Fahs tangerino", Cuadernos de Historia Primitiva del Hombre, 2, 47-51.

BiBLIOgRAFía

Beltrán, A. y Habibi, M. -Coords.- (2008), Historia de la arqueologia en el norte de Marruecos durante periodo del Protectorado y sus referentes en España, Sevilla.

Bernal, D. y otros -Coords.- (2008), En la orilla africana del Círculo del Estrecho: historiografía y proyectos actuales, Tetuán-Cádiz.

Caro Baroja, J. (1972), Los Baroja. Memorias familiares, Madrid.

Castelo, R., Cardito, L. M., Panizo, I. y Rodríguez Casanova, I. (1995), Julio Martínez SantaOlalla. Crónicas de la cultura arqueológica española, Madrid.

(1997), "Julio Martínez Santa-Olalla. Vinculación y contribución a los organismos e instituciones arqueológicas españolas”, La cristalización del pasado: génesis y desarrollo del marco ins- 
titucional de la arqueología en España (G. Mora y M. Díaz-Andreu, Eds.), Málaga, 573580.

Conde de Castillo-Fiel (1948), "El Segundo Congreso Internacional de Africanistas de Bissau (Guinea Portuguesa)", África, 77-78, 44-50.

Coon, S. (1969), Las siete cuevas, Barcelona.

Díaz-Andreu, M. (2002), Historia de la Arqueología. Estudios, Madrid.

Díaz-Andreu, M. y Ramírez, M. (2001), "La Comisaría General de Excavaciones Arqueológicas (1939-1955): la administración del patrimonio arqueológico en España durante la primera etapa de la dictadura franquista", Complutum, 12, 325-344.

Díaz-Andreu, M., Mora, G. y Cortadella, J. -Coords.- (2009), Diccionario histórico de la Arqueología en España, Madrid.

García Figueras, T. (1939), Marruecos, Barcelona.

Gozalbes, E. (2003), "África antigua en la historiografía y arqueología de la época franquista”, $A n$ tigüedad y franquismo (1936-1975), (F. Wulff y M. Álvarez, Eds.), Málaga, 135-160.

(2005), "La arqueología española en Marruecos (1921-1936). Memorias y desmemorias", Documentos inéditos para la Historia de la Arqueología (G. Mora y M. Ayarzagüena, Eds.), Madrid, 183-195.

(2007), "Algunos avatares de la arqueología colonial en el Norte de Marruecos", Boletín de la Asociación Española de Orientalistas, 43, 77-95.

(2012a), Marruecos y el África occidental en la historiografía y arqueología española, Ceuta.

(2012b), Tetuán: Arqueología, Historia y Patrimonio, Tetuán.

(2014), "Pelayo Quintero: la erudición desde la arqueología, la historia del arte y el americanismo", Pelayo Quintero Atauri (1867-1946). El sabio de Uclés (E. Gozalbes, M. J. Parodi y A. Gálvez, Coords.), Cuenca, 107-130.

Gozalbes, E. y Parodi, M. J. (2011), "Miguel Tarradell y la arqueología del Norte de Marruecos", Arqueología y turismo en el Círculo del Estrecho (D. Bernal y otros, Coords.), Tetuán-Cádiz, 105-127.

Gozalbes, E., Parodi, M. J. y Verdugo, J. (2013), "Algunas notas sobre arqueología y colonialismo. La zona española del protectorado marroquí”, Onoba, 1, 261-272.
Gracia Alonso, F. (2008), La arqueología durante el primer franquismo (1939- 1956), Barcelona.

Hencken, H. (1948), “The Prehistoric Archaeology of Tangier Zone, Morocco", Proceedings of the American Philosophical Society, 92 (4), 282288.

Mederos, A. (2003-2004), “Julio Martínez SantaOlalla y la interpretación aria de la Prehistoria de España (1939-1945)”, Boletín del Seminario de Estudios de Arte y Arqueología de Valladolid, 69-70, 13-56.

Ortega, A. I. y Quero, S. (2002), "Julio Martínez Santa-Olalla”, Zona Arqueológica, 1, 195-213.

Parodi, M. J. (2009), "Notas sobre la organización administrativa de las estructuras de gestión del patrimonio arqueológico en el Marruecos septentrional durante el Protectorado (1912-1956)", Herakleion, 2, 117-141.

Parodi, M. J. y Gozalbes, E. (2011), "La arqueología en el Norte de Marruecos (1900-1945", Arqueología y turismo en el Círculo del Estrecho (D. Bernal y otros, Coords.), Tetuán-Cádiz, 137-159. Posac, C. (1949), "Yacimiento del río Nano en el Marruecos español", Cuadernos de Historia Primitiva, 4, 119-123.

Quintero, P. (1941), Apuntes sobre arqueología mauritana de la zona española, Tetuán.

Reymond, G. (2009), "L'Archéologie espagnole entre amateurisme et professionalism. Quelques notes sur le projet phalangist de Julio Martínez Santa-Olalla", Kentron, 25, 91-124.

Robertshaw, P. (1990), A History of African Archaeology, Oxford.

Souville, G. (1973), Atlas préhistorique du Maroc. 1. Le Maroc Atlantique, Paris.

Valderrama, F. (1956), Historia de la acción cultural de España en Marruecos (1912-1956), Tetuán. 